\title{
Globalization and its impact on healthy lifestyle
}

\author{
Rudolf Rybansky ${ }^{1, *}$, Dominik Janos ${ }^{2}$, \\ ${ }^{1}$ Department of Marketing Communication, Faculty of Mass Media, University of Ss. Cyril and \\ Methodius in Trnava, Slovakia \\ ${ }^{2}$ Department of Marketing Communication, Faculty of Mass Media, University of Ss. Cyril and \\ Methodius in Trnava, Slovakia
}

\begin{abstract}
Changes that marketing has noticed since the 21 st century can be characterized as breaking. These are turbulent changes in globalization of the external environment in individual businesses. The changes mainly touch the increasing of amount of products and product lines, brands, shortening the life cycle of products, market segmentation, increasing consumer demand and also problematic acquisition of their attention. Marketing must respond to the changes, even in the context of the globalization process, by changing orientation and focus. As a key can be consider the concentration on maximisation of consumer value and the need to approximate the supply more effectively towards the consumer. Globalization affects businesses to change their marketing communication. The part of globalization is also the creation of a space for implementation of a circular economy with priority to saving and effective using of limited natural resources, streamlining the production of products with high efficiency, low resource consumption and low (or even zero) emission production. A characteristic feature is the prevention and reduction of waste production and subsequently pollutant sources and recycling, so resources are returned to the economic cycle, which has increasingly practical importance. Elements which combine conditions of a circular economy and the impact of globalization need to be constantly evaluated and refined. The paper will point to the characteristic features of circular economy in synergy with globalization. In this paper we focus on the results of our own marketing research, which was implemented to find out the context of applying a healthy lifestyle in the conditions of a circular economy from the perspective of globalization. We used methods of secondary and primary quantitative research.
\end{abstract}

\section{Circular economy in the globalization process}

The priority of a circular economy in the globalization process is the more economical and more effective utilisation of limited natural resources, raising the effectiveness of product manufacturing with high efficiency and low consumption of resources and a low

\footnotetext{
*Corresponding author: dominikjanos16@gmail.com
} 
(or even zero) production of emissions. Part of it lies in the prevention and decrease of waste production, and with it, the prevention and decrease of polluting substance sources, up to and including recycling, where resources are returned back into the economic cycle, a procedure that has an increasingly urgent practical significance. The society of the $21^{\text {st }}$ Century has to face many economic confrontations; e.g. between the supporters of financially demanding environmental protection measures and wealth and power held by multi-national and even global corporations seeking the highest possible profits.[1]

Currently, these issues are highly topical not only in Slovakia, but all the developed countries of the world. For several years, various authors have delved into the circular economy as one of the tools for sustaining a healthy natural evnironment. [2] One part of this field encompasses problem-solving within the context of waste management. The conversion of waste into reusable resources is also one of the basic goals of the plan for effective use of resources. It is necessary to note, that we need to pay the greatest amount of attention to reuse and recycling in particular. [3]

From the perspective of globalization is the circular economy a strategy of long-term sustainable development, through which one can create functional and healthy relations between the natural environment and people. It is understood as an opponent of the linear system. They think about materials the products are made of, the amount of energy used in the production process, the externalities of production or the distribution of product and the options of product disposal.[4] Even though the term is often used as a universal concept of "new world economy", it is also necessary to understand the historic perspectives of its development. Moreover, taking into account the essential paradigmatic and methodological differences between political economy and cultural studies, any complex analysis of globalization processes is indeed truly challenging. [5] The basic principles of the circular economy are based on the idea that the product and material flows are once again returned into the production cycle after use, where they'll become resources important for the creation of new products and services. The goal is to prevent the multiplying of waste. Up until now, the solutions were based on the replacement of primary materials with secondary ones. Recycling was to be the way out of this situation. However, we can't consider this solution to be attractive, given that the overall process is considered as very demanding in terms of energy consumption. In general, we talk about the degradation of materials, which leads to an orientation of demand towards primary materials. With a circular economy, we move beyond the boundaries of recycling. Recycling is based on a renewing industrial system that leads to the termination of waste. We therefore consider recycling to be the outer layer of a circular economy, even though it requires higher energy consumption than the inner layer of the circular economy. The circular economy should serve for the better use of a product's life cycle, and along with that, also minimize the needed energy consumption.

While implementing a circular economy, it is also necessary to resolve inovations and the innovative process. Inovative activities lead to the performance increase of a specific business entity. These activities are connected to the preparation and selling of an original idea. In practice, we describe such activities as ,jump“ innovations. The main goal of innovation activities is the consumer. The new economy creates conditions for a new conception of thinking, based on new knowledge, with the use of information and communication technologies. In accordance with the principles of globalization. It is necessary for environmental awareness to be understood as a part of wide human value system. Environmentally responsible behaviour is type of behaviour, which has the lowest negative impact on the environment and even more - it is beneficial for it.[6]

Innovation and the innovation process is very important to a business, something stressed by J. Čimo in his publication The Role of Innovative Marketing in the Complex Innovation Strategy. [7] 
Concerning European and international documents, one that is frequently mentioned is the so-called Oslo Manual, also known under the title The Measurement of Scientific, Technological and Innovation Activities; Instructions for gathering and interpreting data on innovation, the manual published in its third edition as handbook of the Organisation for Economic Co-operation and Development (OECD) in 2005. The OECD, the European Commission (via Eurostat), as well as the state, all have an important role in the creation of innovation opportunities and simultaneously in the support of an adequate environment for innovations. It is important to note, that from the microeconomic point of view, innovations belong solely to business entities. [8]

A. Zaušková and J. Domová state, that in these definitions, the role of the consumer in the innovation process isn't taken into account, despite the fact that the consumer is the decisive factor in the realisation of innovations. [9]

Many studies are focused on relatively limited field of consumer behaviour impacts on the environment. Because of this, is very important to think about wider context of consumer behaviour - stages of decision making process, impact on the environment and positive/negative contribution to problems with environment. $[10,11,12]$

\section{Methodology}

For the purposes of research, it is immensely important to organise a good quality collection and processing of data. To supplement the information database, it was helpful to carry out marketing research, which occured in three phases. As part of the quantitative research, this effort consisted of secondary data collection, through the study of theoretical source materials including materials of various authors, resources of the Statistical Office of the Slovak Republic, or articles in science magazines. It was then followed by the collection of primary data.

1. Research phase:

We carried out the survey between the 20 September and 20 October 2018. The survey was carried out in two renditions. The electronic rendition was shared publicly on the Facebook social network. The second rendition was carried out by personal contact with a group of randomly selected respondents. The stated renditions were created based on the broad range of the target group, the respondents ranging from 18 to 65 years old. The greater number of respondents was recorded on the social network, older respondents were surveyed through a random selection in the shopping centres of the Trnava region. From the point of view of our survey, it was necessary that all of the queried respondents be citizens from within the Trnava region. We calculated the size of the selected sample with the help of a formula. The basic sample consisted of the inhabitants of the Trnava region, with an age range between 18 and 65 years of age. We based our survey on the statistical data from the Statistical Office of the Slovak Republic, with the basic sample consisting of 420867 people.

\section{Research phase:}

In this phase of the research, we focused on defining the relationship of the individual materials from selected clothing industry products. We subjected the samples to chemical analysis. With the acquired data, we subsequently ascertained, whether there exists a dependency between the level of recycling and the price of selected textile products. To this end, we used a correlation and regression analysis in MS Excel software.

\section{Research phase:}


This phase was focused on acquiring relevant data from the respondents on the subject of shopping choice, the shopping behaviour of consumers within the conditions of a circular economy. The acquired data was subsesequently evaluated based on the evaluation criteria determined in advance, and then charted graphically. The results formed an information base in the creation of recommendations for the improvement of the current status of implementing the principles of a circular economy in Slovakia. The subsequent observance of the given principles will help secure the protection of the natural environment.

\section{Equations and mathematics}

Because the range of products is very wide and our goal is to research the individual production areas in greater detail, we have decided to focus our following research on clothing industry products used by sportsmen. This narrow specialisation is intentionally aimed at products that we use in our daily life on a stable basis. In the conclusion, the results of our research will be generalised to all products of the clothing industry.

The target group of our survey was divided into three age categories, specifically, people between 18 to 30 years old constituted 24\%, the group between 31 and 50 years of age constituted $39 \%$, and the last group, in the age range of 51 to 65 years was represented by $37 \%$. Thanks to this percentual division as well, it becomes clear, that we were trying to adress all the categories in the target group with almost the same amount of respondents.

We asked the respondents about the frequency of their shopping for clothes, clothing industry products. Based on the evaluation of replies, we found out that $45 \%$ of the queried shops for clothes at least once $(1 \mathrm{x})$ every 3 months. This was followed by a group of 96 respondents, which goes shopping once $(1 \mathrm{x})$ a month. 85 of the queried respondents shops at least once $(1 \mathrm{x})$ every six months, and the group with the lowest frequency of shopping, only once $(1 \mathrm{x})$ in a year, constitutes $8 \%$.

We were surveying, whether the respondents from our selected sample follow the individual communication tools during the process of shopping for clothes. It is interesting that as many as 162 of all queried respondents did not know how to answer the question. 119 respondents replied positively and 104 respondents commented that communication tools play no role in their shopping process.

We directed our attention at ascertaining the knowledge of the queried respondents on the individual principles of the circular economy, on the sample of clothing industry products. The most surprising find for us was that as many as 177 respondents did not know the features of the circular economy in the clothing industry. 123 respondents had a grasp on this area and 85 of the queried respondents had no knowledge at all on the working principle of a circular economy.

For improving marketing communication in the conditions of the circular economy, we have chosen several samples of textiles. We subjected these to a chemical analysis, with the goal of defining material items of the individual textiles. 
Table 1. Charakteristics of textile article samples

\begin{tabular}{|c|c|c|}
\hline $\begin{array}{c}\text { Textile } \\
\text { article type }\end{array}$ & Price & $\begin{array}{c}\text { Sample } \\
\text { number }\end{array}$ \\
\hline Socks & Higher & 1 \\
\hline Socks & Lower & 2 \\
\hline T-shirt & Higher & 3 \\
\hline T-shirt & Lower & 4 \\
\hline $\begin{array}{c}\text { Tracksuit/ } \\
\text { Sweats set }\end{array}$ & Higher & 5 \\
\hline $\begin{array}{c}\text { Tracksuit/ } \\
\text { Sweats set }\end{array}$ & Medium & 6 \\
\hline $\begin{array}{c}\text { Tracksuit/ } \\
\text { Sweats set }\end{array}$ & Lower & 7 \\
\hline
\end{tabular}

Results of the material composition of the individual samples:

Table 2. Sample no. 1

\begin{tabular}{|c|c|c|}
\hline Material & $\mathbf{\%}$ & Note \\
\hline Cotton & 78 & \\
\hline Polyamide & 18 & $\begin{array}{c}\text { Hollow } \\
\text { thread }\end{array}$ \\
\hline $\begin{array}{c}\text { Rubber } \\
\text { spandex }\end{array}$ & 4 & \\
\hline
\end{tabular}

Table 3. Sample no. 2

\begin{tabular}{|c|c|c|}
\hline Material & $\%$ & Note \\
\hline Cotton & 82 & \\
\hline Polyamide & 16 & \\
\hline $\begin{array}{c}\text { Rubber } \\
\text { spandex }\end{array}$ & 4 & \\
\hline
\end{tabular}


Table 4. Sample no. 3

\begin{tabular}{|c|c|c|}
\hline Material & $\%$ & Note \\
\hline Polyethylene & 85 & \\
\hline Elastane & 15 & \\
\hline
\end{tabular}

Table 5. Sample no. 4

\begin{tabular}{|c|c|c|}
\hline Material & $\%$ & Note \\
\hline Polyethylene & 80 & \\
\hline $\begin{array}{c}\text { Lycra - } \\
\text { rubber }\end{array}$ & 20 & \\
\hline
\end{tabular}

Table 6. Sample no. 5

\begin{tabular}{|c|c|c|}
\hline Material & \% & Note \\
\hline Cotton & 82 & \\
\hline $\begin{array}{l}\text { Lycra - } \\
\text { rubber }\end{array}$ & 18 & \\
\hline
\end{tabular}

Table 7. Sample no. 6

\begin{tabular}{|c|c|c|}
\hline Material & \% & Note \\
\hline Polyester & 55 & $\begin{array}{c}\text { Hollow } \\
\text { thread }\end{array}$ \\
\hline Cotton & 40 & \\
\hline Elastane & 5 & \\
\hline
\end{tabular}

Table 8. Sample no. 7

\begin{tabular}{|c|c|c|}
\hline Material & \% & Note \\
\hline Polyester & $\mathbf{9 6}$ & \\
\hline Elastane & 4 & \\
\hline
\end{tabular}


In the next phase of the research, we processed a questionnaire survey focused on the utilisation of tools of the communication mix in selected segments within the context of consumer behaviour. Here, we only present the results of the key findings, that directly influence shopping behaviour and the decision-making process of the end consumers.

Does familiarity with the principles of a circular economy influence your shopping decisions?

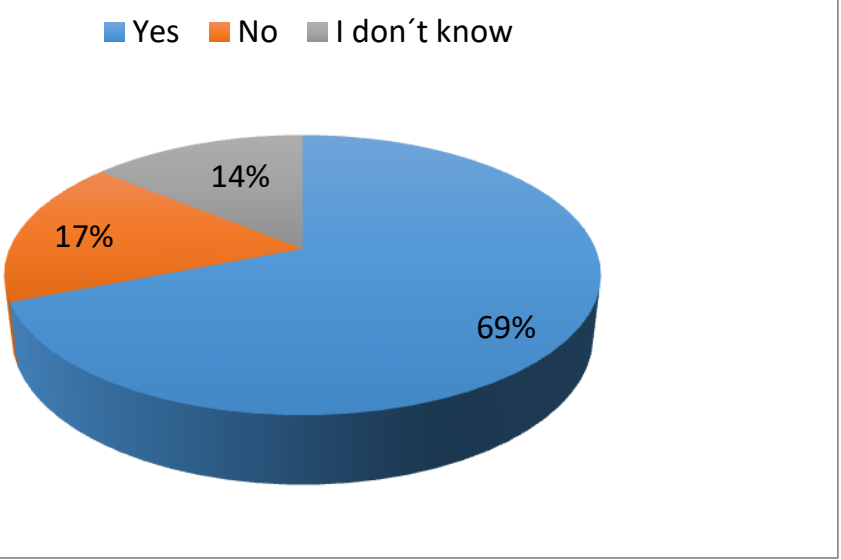

Graph 1. Familiarity with the principles of a circular economy

Based on the results, we can observe that as many as $69 \%$ of queried respondents are influenced by the principles of a circular economy in their shopping decisions.

Suggest forms of product promotion within the context of environmentally friendly products.

\author{
Advertising \\ Presentation of products \\ Retraining of retail personnel \\ Promotion of environmentaly-friendly products in the media
}

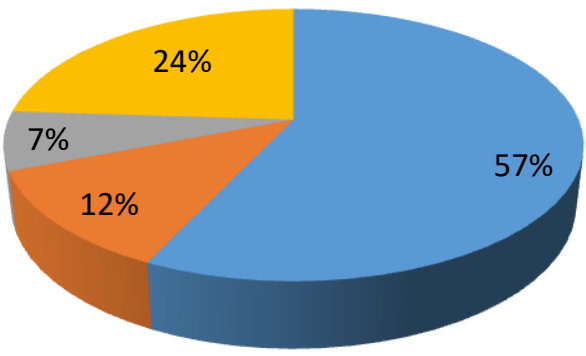

Graph 2. Forms of promotion for environmentally-friendly products 
The result of this question is assessed by the proposal of promotional forms for environmentally-friendly products. After assessing the most commonly occuring answers, we can observe that the queried respondents propose utilising all forms of marketing communication, but as many as $57 \%$ prefer advertising.

\subsection{Discussion}

In the current situation, not only governments, but also the public, including individial companies, are beginning to recognize the need to introduce long-term sustainable approaches to economic development. This results in the fact that even customers demand the guaranteeing of a competitive advantage, they demand non-faulty products, suitable for both their health concerns and for the natural environment. In the present, business owners in Slovakia are also beginning to utilise the tools of a circular economy and green innovations in accordance with the principles of globalization. The two greatest issues that emerge from our surveys are climate change and economic crises. The results hint that the rate of innovation and technological progress is currently at a very low level. Applying the individual models of a circular economy is a long-term process and in Slovakia, currently at a very weak level. The results hint that innovations are the basic element of a cyclical type of economy.

Assessing the specific acquired data, we note that the rate of awareness among the populace, about the area of environmentally friendly innovations and of the implementation of a circular economy, is at a relatively low level.

The results definitely show us the need for an accelerated spread of information concerning the preserving of a healthy natural environment. Even though, in the present, some early examples focused on these issues have started to appear (e.g. a protected workshop in eastern Slovakia experimentally producing new material from textile and plastic waste, the new material is then used to manufacture simple shopping bags). Due to principles of globalization. Based on the chemical analyses of materials and the prices of individual textiles, we examined the dependence of price and recycling of the researched samples. The results showed that there is a very low recyclability of individual products if the textile product prices are low. Because of this reason, it is very important to influence shopping choice and susbequently the shopping behaviour of consumers, in order to raise awareness that the purchasing of cheap textiles leads to the degrading of the natural environment.

Based on the results of evaluating the third phase, it is clear that it is necessary to pay great attention to creating an appropriate promotion for environmentally-friendly products, in conjunction with the individual tools of marketing communication. The most important areas for improving the current state of things is the area of providing information on the outside of the products themselves, the improvement of communication skills of retail personnel and the area of selecting appropriate communication channels for communication and informing about improvement of globalization principles.

\section{Conclusion}

All companies in Slovakia, from the perspective of globalization processes as well, endeavour to overcome their competition by utilising all the available means. The applying of innovations also belongs under these available means. Applying innovations ensures companies the option to introduce a unique product to the market or generate a unique value in an already realised product. It represents a tool with which they create their competitive advantage. It is necessary to note that properly selected promotion plays a big 
role in the introduction of innovations. This factor influences the earliness of introducing an innovation to the market. [13,14,15]

Our research had also confirmed, that the circular economy represents new possibilities for businesses at exercising their positions on the market and creates an opportunity for them to exploit gaps on the market. Based on the results show that introducing some types of innovations requires a high degree of investment, but in many cases, the rate of return in a well-selected innovation policy is very fast. The circular economy, which has an influence on the practical exertion of companies, influences environmental protection to a great degree, and also has an influence that reaches a new consumer style of thinking among customers, respecting globalization factors.

This trend of applying similar innovations will continue to grow in the following years, as there is no sign of its stagnation in the present. We can observe that this trend has an upward growth development and is supported in various ways, e.g. the programmes of the European Union. Therefore, Slovak companies in the near future must preserve their dynamic development, which was defined within the context of a circular economy, and fully carry out the necessary measures on all levels, in order to make a cyclical economy real and to the benefit of the entire society.

This paper is an output of the research project supported by the Grant Agency of the Ministry of Education of the Slovak Republic and the Slovak Academy of Sciences (VEGA) No. 1/0078/18 titled Aspects of Marketing Communication in the Management Processes of Circular Economy.

\section{References}

1. J. Radosinska, J. Visnovsky, Transformations of Public Sphere in the Era of Digital Media. European Journal of Science and Theology 12, 85-96 (2016)

2. S. Sauve, S. Bernard, P. Sloan, Environmental sciences, sustainable development and circular economy, Environmental development 17 48-49 (2016)

3. Ellen Macarthur Foundation, The circular model - an overview. European Journal of Operational Research 211, 170-183 (2013)

4. Z. Musova, H. Musa, L. Ludhova, Environmentally responsible purchasing in Slovakia. Economics \& Sociology 11, 289-305, (2018)

5. J. Radosinska, Media Culture as a Part of Globalization Processes. Media and Globalization : Different Cultures, Societies, Political Systems, 17-31 (2015)

6. L. Steg, C. Vlek, Encouraging pro-environmental behavior: an integrative review and research agenda. Journal of Environmental Psychology 29, 309-3017 (2009)

7. J. Cimo, Uloha inovativneho marketingu v komplexnej inovacnej strategii. Economic review 39, 120 (2010)

8. OECD. (n.d.). Environment. [Online]. Available at: http://www.oecd.org/environment

9. A. Zauskova, A., J. Domova, Inovacna schopnost a inovacna vykonnost podnikatelskych subjektov. (University of Ss. Cyril and Methodius in Trnava, Slovakia, 2012)

10. N. Oneil, A. Mukherjee, Consumer knowledge in pro-environmental behavior: An exploration of its antecedents and consequences. World Journal of Science, Technology and Sustainable Development 13, 328-352 (2016)

11. A. Siekelova, The role of the receivables management in conditions of globalization. 15th International Scientific Conference on Globalization and its Socio-Economic Consequences. Rajecke Teplice, Slovakia, 686-690 (2015) 
12. M. Sehrawat, A.K. Giri, Globalization, role of institutions and economic performance in Indian economy Empirical evidence. Journal of financial economic policy 11, 82100 (2019)

13. J. Heymann, A. Earle, K. McNeill, The impact of Labor Polices on the Health of Young Children in the Context of Economic Globalization. Annual Review of Public Health 34, 355-372 (2013)

14. K.H. O'Rourke, Economic history and contemporary challenges to globalization. Journal of Economic History 79, 356-382 (2019)

15. L. Linsi, D.K. Mugge, Globalization and the growing defects of international economic statistics. Review of International Political Economy 26, 361-383 (2019) 